\title{
Magnetic Resonance Evaluation of the Cerebral Circulation in Obstructive Arterial Disease
}

\author{
Peter Jan van Laar ${ }^{\mathrm{a}}$ Jeroen van der Grond ${ }^{\mathrm{b}}$ Willem P.T.M. Mali ${ }^{\mathrm{a}}$ \\ Jeroen Hendrikse ${ }^{a}$ \\ a Department of Radiology, University Medical Center, Utrecht, and ${ }^{\mathrm{b}}$ Department of Radiology, \\ Leiden University Medical Center, Leiden, The Netherlands
}

\section{Key Words}

Magnetic resonance imaging $\cdot$ Cerebral blood flow .

Steno-occlusive disease

\begin{abstract}
Background: The aim of the current overview is to highlight the possibilities of magnetic resonance imaging (MRI) in the assessment of patients with obstructive arterial disease. The anatomic and hemodynamic aspects of the extra- and intracranial cerebral circulation were analyzed and show the importance of combining both aspects in studying cerebral hemodynamic changes. $\boldsymbol{R} \boldsymbol{e}$ sults: Three levels of cerebral circulation are distinguished: blood flow to the brain (level 1); the distribution of blood flow in the brain (level 2), and finally perfusion of the brain (level 3). To investigate the anatomy of the arteries in the neck and the circle of Willis, contrast-enhanced, time-of-flight and phase contrast MR angiography (MRA) are available. To evaluate the hemodynamics at the 1st and 2nd level of the cerebral circulation twodimensional phase contrast (volume flow and flow direction) MRA can be used. In addition, the distribution of blood via the circle of Willis can be visualized with dynamic MRA. At the 3rd level, measurements of regional brain perfusion can be obtained by injecting gadolinium,
\end{abstract}

dynamic susceptibility contrast MRI, or noninvasively with arterial spin labeling (ASL) MRI. In addition, selective ASL MRI is able to evaluate the perfused territories of individual brain-feeding arteries. Conclusion: The currently available MR techniques allow evaluation of the cerebral circulation from the aortic arch upwards towards the microvasculature and brain tissue perfusion in a comprehensive 20-min protocol. The combined use of the described MR methods in patients with steno-occlusive disease will further clarify the pathophysiological relations between the vasculature, perfusion and brain function.

Copyright (C) 2006 S. Karger AG, Basel

\section{Introduction}

The presence of adequate cerebral circulation is essential to maintain cerebral perfusion and brain function [1-4]. From the aortic arch upwards, arterial blood flows via the internal carotid arteries (ICAs) and vertebrobasilar arteries (VBAs) to the brain and is distributed intracranially at the level of the circle of Willis into the anterior, middle and posterior cerebral arteries (ACA, MCA and PCA). Although it is widely acknowledged that large inter-individual variation exists in the anatomy of the

\section{KARGER \\ Fax +4161306 1234 E-Mail karger@karger.ch} www.karger.com
(C) 2006 S. Karger AG, Basel $1015-9770 / 06 / 0216-0297 \$ 23.50 / 0$

Accessible online at: www.karger.com/ced
Peter Jan van Laar, MD

Department of Radiology (Hp E01.332), University Medical Center Utrecht PO Box 85500

NL-3508 GA Utrecht (The Netherlands)

Tel. +31 30250 8385, Fax +31 30258 1098, E-Mail p.j.vanlaar@azu.nl 
cerebral circulation [5], less is known about the hemodynamic consequences of anatomic arterial variation in patients with steno-occlusive disease.

In the present overview we distinguish three levels of cerebral circulation: blood flow to the brain (1st level, the arteries in the neck); the distribution of blood flow in the brain (2nd level, the circle of Willis), and finally perfusion of the brain ( $3 r d$ level). In the last 30 years a vast amount of studies have demonstrated the prognostic importance of anatomical and hemodynamic information obtained at the individual level [3, 4, 6-11]. The versatility of modern imaging methods allows integration of the information obtained at all three levels, enhancing the therapeutic decision in individual patients presenting with obstructive arterial disease [12]. Especially in the field of magnetic resonance (MR) imaging (MRI), major progress has been made in optimizing MR angiography (MRA) and MR perfusion techniques to evaluate the cerebral circulation in occlusive disease. The aim of the current overview is to enlighten the possibilities of MRI to assess the anatomic and hemodynamic aspects of the extra- and intracranial cerebral circulation and to show the importance of the combination of both aspects in studying the cerebral circulation. In this respect we aim to focus on patients with large artery steno-occlusive disease.

\section{Flow to the Brain (1st Level)}

Adequate blood flow in the major brain-feeding arteries in the neck is the basis of maintaining cerebral blood flow (CBF). This section describes the available MR techniques to investigate differences in anatomy of the ICAs and VBAs and the subsequent hemodynamic consequences.

\section{Anatomy}

For morphological evaluation of the ICAs and VBAs three MRA methods are currently available: time-offlight (TOF); phase contrast (PC), and contrast-enhanced (CE) MRA. The TOF method is a technique in which visualization of the arterial lumen is achieved by the inflow of fresh (unsaturated) blood through an image section with pre-saturated static tissue [13]. Either two-dimensional (2D) or three-dimensional (3D) TOF MRA techniques can be performed. In 2D TOF MRA thin slices are acquired one after another, reducing the saturation effects of the MR pulses on the blood and increasing the sensitivity for arterial inflow. Consequently, 2D TOF
MRA is suited to visualize slow flow relative to $3 \mathrm{D}$ TOF in which a larger imaging volume is acquired simultaneously. In general, with 3D TOF MRA a larger trajectory of arteries is visualized with a high spatial resolution and a high signal-to-noise ratio. A drawback of TOF MRAbased techniques is the potential occurrence of flow void artifacts, particularly distal to a severe arterial stenosis due to turbulence of the blood flow $[14,15]$.

While TOF MRA depends on the refreshment of inflowing blood into a slice, PC MRA employs the phase shift in the signal that is induced by the flowing blood. This phase shift is proportional to velocity and there is a direct correlation with signal intensity. Therefore, with PC MRA small vessels can be clearly visualized, even with slowly flowing blood. PC MRA is applicable for both 2D and 3D acquisition. 2D PC MRA is especially valuable as a survey scan, and phase velocity maps can be constructed for quantitative measurements of blood volume $(\mathrm{ml} / \mathrm{min})$ flowing through a vessel. A disadvantage of 3D PC MRA is the relatively long acquisition time and the presence of venous overprojection.

A relatively recent development in MRA is CE MRA [16-18]. With the injection of an intravenous contrast bolus of gadolinium the $\mathrm{T} 1$ of the blood is shortened and larger flip angles can be used to generate a stronger signal with improved background suppression and less signal saturation. CE MRA provides morphological information over a long track of the neck arteries from the origin up to the circle of Willis. For CE MRA fast scan times and adequate timing based on a test bolus are required to avoid venous overprojection of the jugular veins. After a test bolus currently available CE MRA methods acquire a high-contrast arterial signal in the first $10 \mathrm{~s}$, within the time window of arterial enhancement. Thereafter, the acquisition is continued to increase the resolution of the depicted arteries. The obtained high spatial resolution allows excellent visualization of near-occlusions of the brain-feeding arteries and flow-related artifacts are strongly diminished.

After image acquisition, maximum intensity projections can be reconstructed from 3D TOF, 3D PC or CE MRA datasets. The maximum intensity projection images can be projected in any plane to provide multiple views of the vascular anatomy (fig. 1). With the large 'reach' of CE MRA even the origin of the common carotid arteries can be visualized. Furthermore, 3D TOF, 3D PC and CE MRA can demonstrate the anatomical variation in the ICAs and VBAs such as vascular elongation, or kinking and coiling. For measurements of ICA stenosis, a series of studies compared the diagnostic per- 
Fig. 1. Examples of maximum intensity projections of contrast-enhanced MRA investigations of the neck arteries. a An example of contrast-enhanced MRA investigation of the brain-feeding arteries from the origin of the arteries at the aortic arch upwards intracranially to the circle of Willis. This image demonstrates a left-sided internal carotid artery occlusion and an anatomical variation of the left-sided vertebral artery, which terminates in the posterior inferior cerebellar artery. b This contrast-enhanced MRA image shows bilateral occlusion of the internal carotid artery and feeding of the brain via the vertebrobasilar arteries.
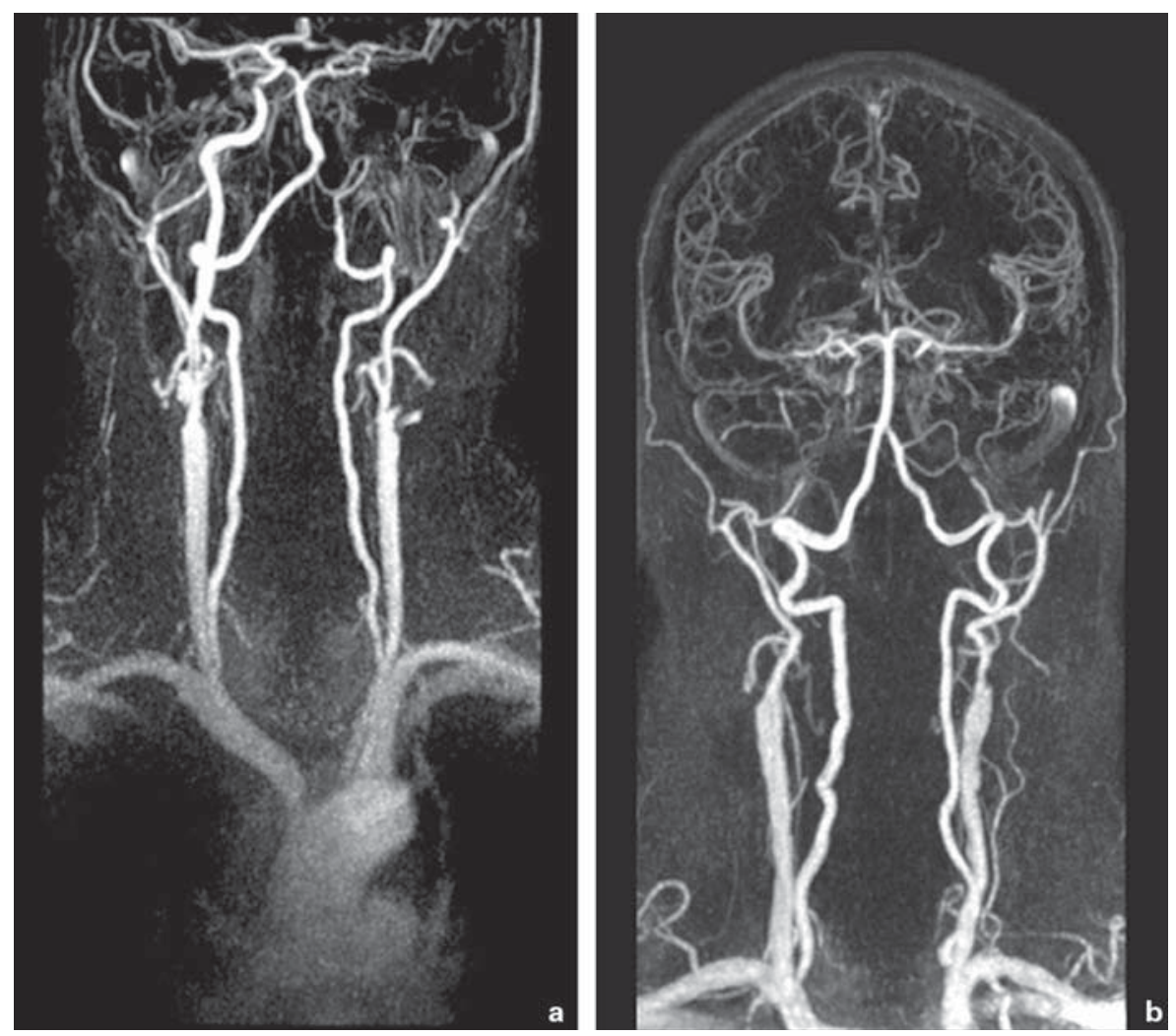

formance of MRA techniques relative to the gold standard, intra-arterial digital subtraction angiography [16, 19, 20]. Most recent studies showed high sensitivities and specificities of especially CE MRA for the detection of a stenosis of $>70 \%$ according to the North American Symptomatic Carotid Surgery Trial criteria [17, 21]. With the high resolution of CE MRA extracranial sources of collateral circulation can be visualized, for instance the arterial connections between the branches of the external carotid artery and the intracranial vasculature. With respect to the VBA the variable origin of these arteries can be demonstrated in addition to the dominance of a single vertebral artery, hypoplasia of a vertebral artery or the presence of a subclavian steal syndrome $[5,22]$.

\section{Hemodynamics}

Although vessels may be visualized on intra-arterial digital subtraction angiography or MRA, there are only limited methods available to quantitatively evaluate blood flow through the individual brain-feeding vessels. Quantitative volume flow $(\mathrm{ml} / \mathrm{min})$ measurements in the ICAs and the basilar artery (BA) can be performed with
2D PC MRA [23-25]. Figure 2 illustrates the typical positioning of such a 2D PC MRA slice to measure flow in both ICAs and BA simultaneously. This MRA flow measurement can either be performed with or without cardiac triggering, and validation studies on the quantification of volume flow values of both approaches have been performed [26-29]. 2D PC MRA studies showed that the total volume flow (ICAs and BA) in a normal population is on average $600 \mathrm{ml} / \mathrm{min}$. About $40 \%$ of the total flow is distributed via a single ICA and $20 \%$ via the BA, however these relative contributions are changing with stenoocclusive disease of the ICAs or VBAs [30]. With a $>70 \%$ stenosed ICA, the flow contribution of the contralateral ICA and BA rises significantly [30]. In the extreme example of patients with severe atherosclerotic disease and occlusion of both ICAs a 2.5 -fold increase in flow of the BA has been documented [30]. Even in patients without steno-occlusive disease, variations in the anatomy of the circle of Willis are highly correlated with the relative contributions of the ICAs and BA [31]. In subjects with a missing A1 segment the volume flow in the contralateral ICA, feeding both ACAs, is significantly higher compared with the volume flow of the ipsilateral ICA. Furthermore, 


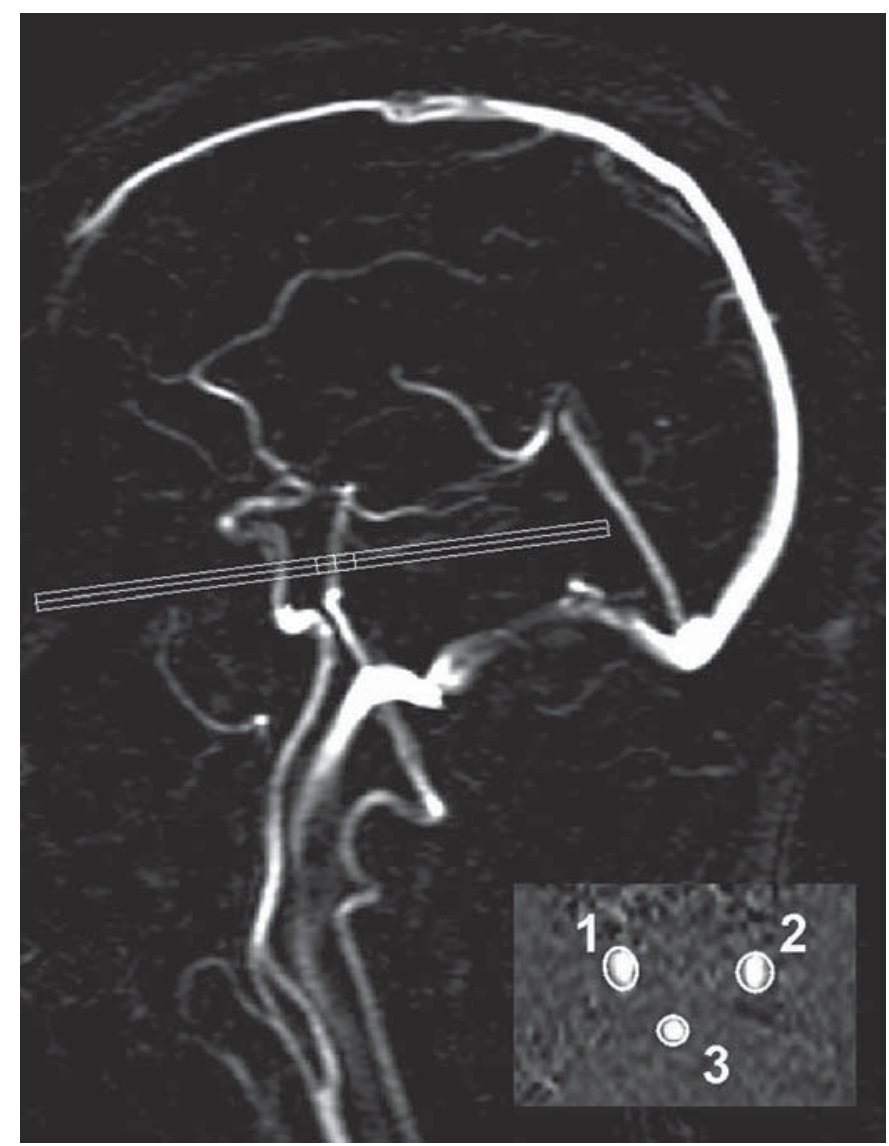

Fig. 2. Typical positioning of a 2-dimensional phase-contrast MRA slice through the internal carotid arteries and the basilar artery. Quantitative volume flow $(\mathrm{ml} / \mathrm{min})$ measurements are obtained by integrating across manually drawn regions-of-interest that enclose the vessels. Inset: 1 = right internal carotid artery; 2 = left internal carotid artery; 3 = basilar artery.

with a unilateral or bilateral fetal-type feeding of the PCA from the ipsilateral ICA, the volume flow in the ICA on the side of the fetal-type PCA is increased and the BA flow is decreased. In subjects with a bilateral fetal-type feeding of the PCA the volume flow in the BA is only $50 \%$ compared with subjects with a non-variant circle of Willis. These findings indicate that large asymmetries in volume flow between the right and left ICAs or decreased volume flow in the BA are not necessarily based on vascular pathology but may be due to variations in the anatomy of the circle of Willis. Absolute measurements of volume flow in the ICAs and BA should always be accompanied by an evaluation of the anatomy of the circle of Willis.

\section{Circle of Willis (2nd Level)}

The circle of Willis is a vascular structure that is capable of rerouting blood flow at the level of the scull base from the posterior to anterior circulation via the posterior communicating artery $(\mathrm{PCoA})$ or vice versa, or from one hemisphere to the other hemisphere via the anterior communicating artery (ACOA). The circle of Willis is considered a highly effective collateral pathway to maintain adequate cerebral perfusion in case of diminished arterial perfusion pressure in the ICAs and VBAs in case of severe stenosis or occlusion.

\section{Anatomy}

For the evaluation of the anatomy of the circle of Willis, TOF, PC or CE MRA methods can be applied. Most frequently, a 3D TOF MRA volume is acquired which provides morphological information on both the circle of Willis and its branching vessels. Population studies performed with TOF MRA have demonstrated a large interindividual variability in the anatomy of the circle of Willis $[32,33]$. The most important variation in the circle of Willis is the one in which the PCoA is hypoplastic or absent $(<40 \%)$. Another frequently observed anatomical variation in the circle of Willis is unilateral dominant feeding of the PCA via the ipsilateral ICA. This so-called fetal-type PCA has a prevalence of $25 \%$ and the bilateral fetal-type has a prevalence of approximately $10 \%$. In the anterior part of the circle of Willis in about one fifth of all subjects an absent ACoA was found. In addition, in $5-10 \%$ a hypoplastic or absent A1 was found. In these cases, both ACAs were supplied from a single ICA via the ACoA.

Diameter measurements of the component vessels of the circle of Willis have been performed on 3D TOF MRA, both in population studies and in the presence of cerebrovascular disease [32, 34-36]. However, these diameter measurements should be interpreted with caution because the actual vessel lumen will be underestimated because of the very slow flow near the vessel wall [37].

With the large reach of the current CE MRA protocols of the neck, the circle of Willis falls often within the scan range and can be evaluated. CE MRA of the intracranial vasculature alone can be performed to provide high-contrast morphological information on the circle of Willis. Although PC MRA can be used for anatomical information on the intracranial vasculature, 2D and 3D PC MRA methods are most commonly used to demonstrate the flow direction and presence of collateral flow via the circle of Willis. 


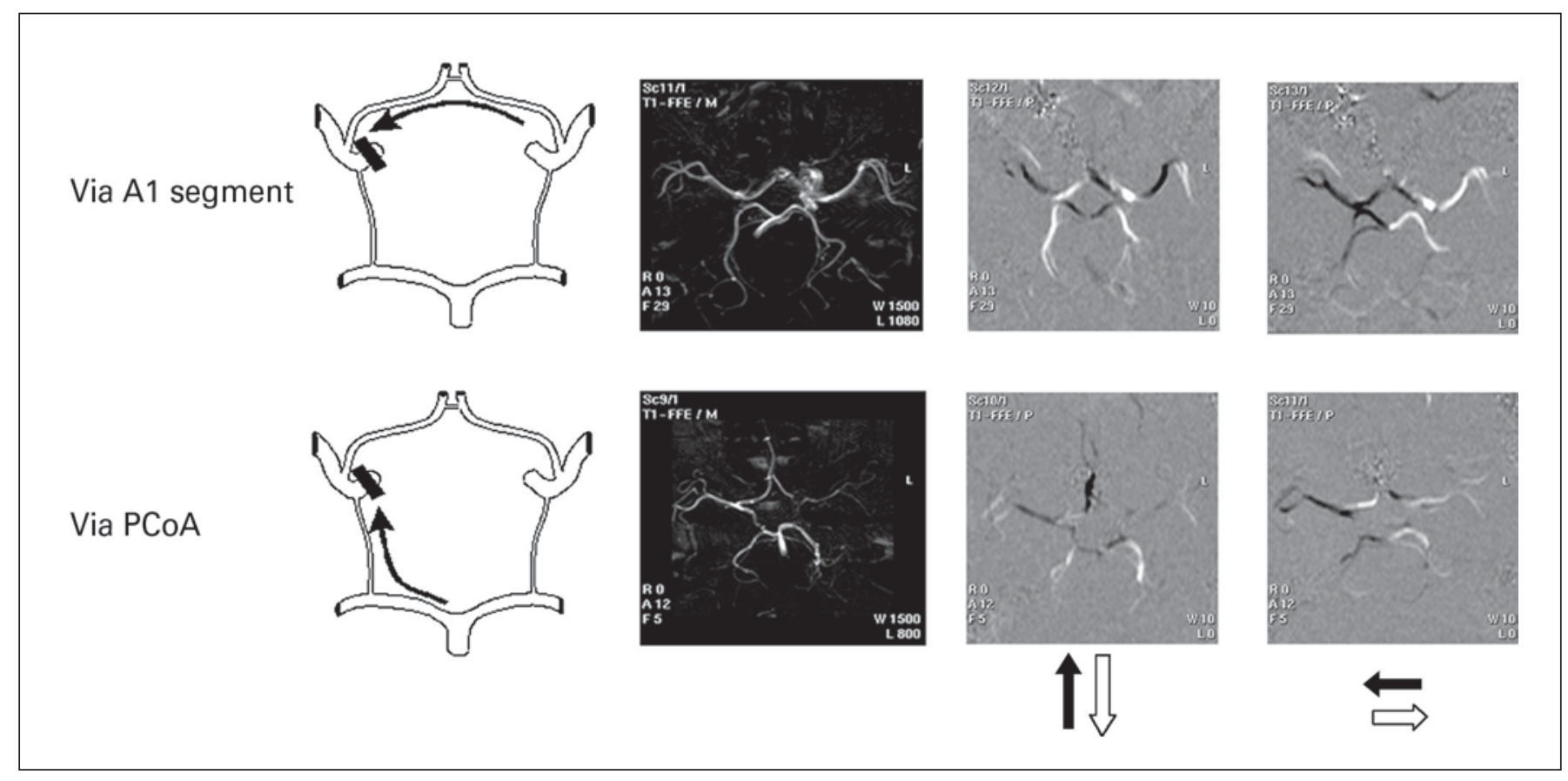

Fig. 3. Examples of MRA investigations of anatomy and function of the circle of Willis in 2 patients with a right-sided symptomatic occlusion of the internal carotid artery. Each row of images represents a patient. The first column of drawings shows two patterns of collateral flow via the circle of Willis to the hemisphere ipsilateral to an occluded carotid artery. The second column shows maximum intensity projections of the circle of Willis as investigated with 3-dimensional time-of-flight MRA. The third column shows 2-dimensional phase-contrast MRA images phase-encoded in the anterior-posterior direction: blood flowing in the anterior direction is black and blood flowing in the posterior direction is white. The last column shows the 2-dimensional phase-contrast MRA images phase-encoded in the left-right direction: blood flowing to the right is black and blood flowing to the left is white. Collateral flow via the A1 segment can be detected on the images encoded in the leftright direction (last column). Collateral flow via the posterior communicating artery (PCoA) can be detected on the images phase-encoded in the anterior-posterior direction. A1 segment = A1 segment of the anterior cerebral artery.

\section{Hemodynamics}

When blood flows in opposite directions, it causes opposite phase changes in the MR signal on PC MRA, the property of which can be used to detect collateral flow via the anterior and posterior circle of Willis [35, 38-40]. PC MRA is most frequently used for flow encoding in two directions: anterior-posterior and left-right direction [41, 42]. The image plane encoded in the anterior-posterior and left-right direction enables straightforward interpretation on the basis of the black and white contrast of the blood flowing in opposite directions (fig. 3). Collateral flow via the PCoA is best detected on the image phases encoded in the anterior-posterior direction. Collateral flow via the ACoA towards the MCA is demonstrated by the detection of retrograde flow via the A1 segment, which can be demonstrated both on the 2D PC MRA images phase encoded in the anterior-posterior and left-right direction. In practice, these 2D PC MRA images are inter- preted in combination with the 3D TOF MRA images, demonstrating the anatomy of the circle of Willis. Similar to the 2D PC MRA quantitative volume flow ( $\mathrm{ml} / \mathrm{min}$ ) measurements of the arteries in the neck, flow quantification of the branches of the circle of Willis can be obtained [43].

In addition to flow directional and flow volume measurements, the distribution of blood flow via the circle of Willis can be imaged dynamically [44-47]. CE MRA with multiple acquisitions can be performed to evaluation the passage of the contrast bolus through the cerebral vasculature $[45,46]$. Furthermore, dynamic MRA measurements can be obtained with proximal labeling (saturation or inversion preparation) of the arterial blood, which is used as an endogenous tracer. After the labeling, image acquisition with a high temporal resolution can demonstrate the collateral filling of branches of the circle of Willis $[44,48]$. 

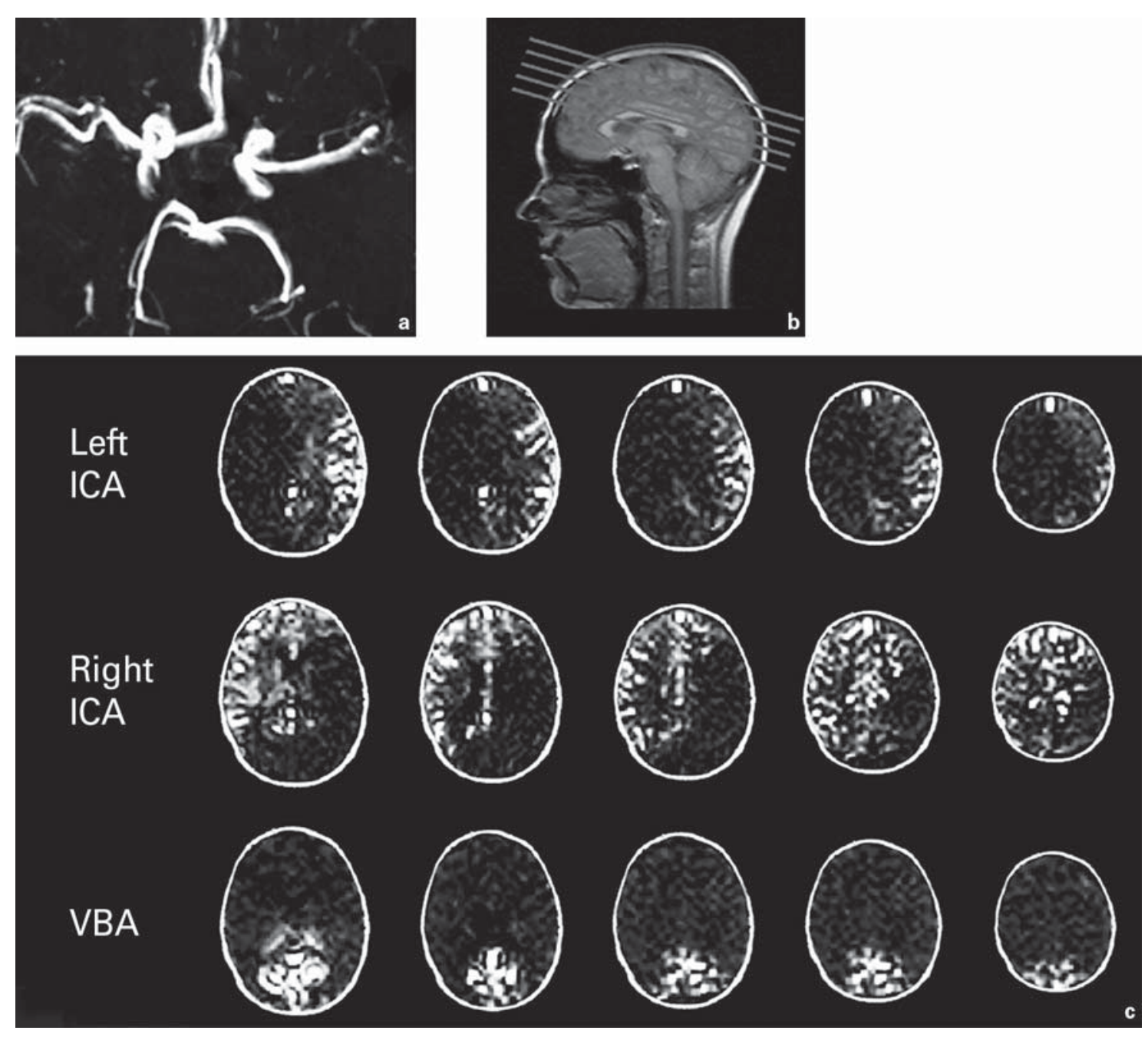

Fig. 4. Example of representative flow territory images investigated with noninvasive selective arterial spin labeling MRI of the individual internal carotid arteries (ICAs) and the posterior circulation (vertebrobasilar arteries, VBAs) in a subject with a missing A1 segment of the anterior cerebral artery. a Corresponding maximum intensity projections of the circle of Willis with a missing A1 segment of the left anterior cerebral artery investigated with 3-dimensional time-of-flight MRA. b Planning of the five imaging slices parallel to the orbitomeatal angle. c Regional perfusion images of the flow territories of the individual ICAs and posterior circulation. After labeling of the left ICA, the perfusion signal is present only in the left middle cerebral artery flow territory, while the anterior cerebral artery flow territory is absent. After labeling the right ICA, the perfusion signal is present in the right middle cerebral artery flow territory and both left and right anterior cerebral artery flow territories.

\section{Brain Perfusion (3rd Level)}

Cerebral perfusion is the basis for the delivery of oxygen and nutrients to maintain brain function. This section describes the available MR techniques to investigate the anatomy and hemodynamics of brain tissue perfusion.

\section{Anatomy}

In addition to the anatomy of the circle of Willis the currently available TOF and CE MRA methods can demonstrate the branching vessels of the circle of Willis and detect steno-occlusive lesions in the proximal parts of the ACA, MCA and PCA. Recently, MR flow territory imaging methods have been introduced which allow visualization of the extension of the distal branches of the ACA, 


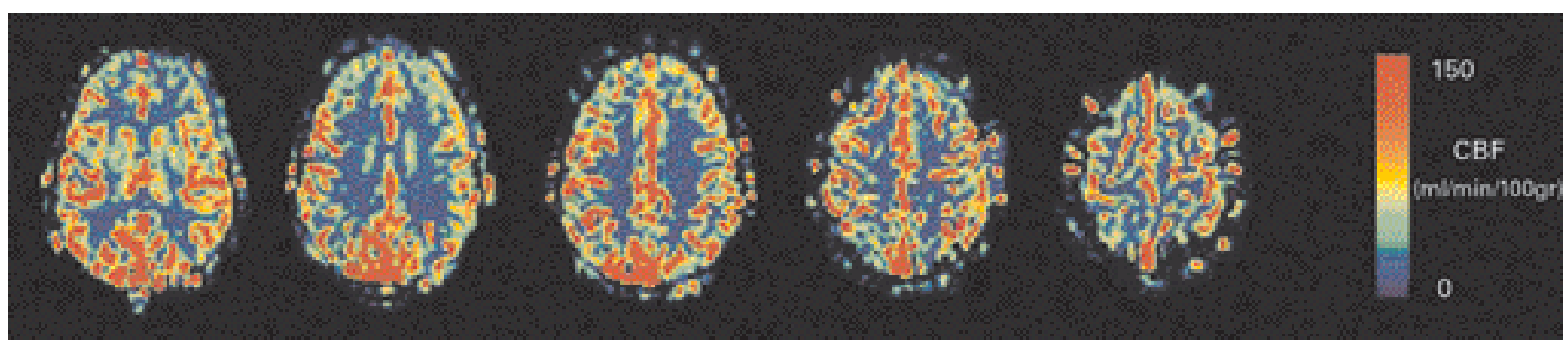

Fig. 5. Example of a cerebral blood flow $(\mathrm{CBF}, \mathrm{ml} / \mathrm{min} / 100 \mathrm{~g}$ tissue) map of a subject investigated with pulsed arterial spin labeling MRI. The shades correspond to the shade bar indicating the cerebral blood flow $(\mathrm{ml} / \mathrm{min} / 100 \mathrm{~g}$ tissue).

MCA and PCA [49-52]. These methods are different implementations of arterial spin labeling (ASL). In ASL MRI the protons of the arterial water in the feeding vasculature of the brain are magnetically labeled and used as an endogenous tracer. A labeling delay allows the labeled arterial water protons to flow through the arterial vascular tree and exchange with the unlabeled brain tissue water. The subsequent change in tissue magnetization is restricted to the flow territory of the labeled artery. The first selective ASL methods were based on the use of a local surface coil with selective labeling of a single ICA reached by the small penetration depth of this surface coil [53, 54]. Another selective ASL approach is based on angulation of a labeling slab to reach selectivity for either a single ICA or the VBA (fig. 4) [49]. Planning of these labeling slabs is based on anatomical MRA scans of the brain vasculature. Several other methods for selective labeling of the ICA have been introduced, however all these methods are both sensitive for variations at the level of the circle of Willis as well as the extension of the flow territory of the ACA, MCA and PCA [50, 51, 55]. Recently, an ASL method for selective labeling of the ACA, MCA and PCA has been introduced based on a rotating labeling frame [52]. Selective ASL flow territory measurements have demonstrated the large inter-individual variability in flow territories in vivo, which were previously demonstrated in postmortem studies [56, 57]. In patients with cerebrovascular disease selective ASL can demonstrate a decrease in flow territory with the presence of steno-occlusive disease and increase in flow territory with the presence of compensatory collateral flow. In addition to flow territory measurements the regional CBF contribution of each individual artery can be obtained.

Magnetic Resonance Evaluation of Cerebral Circulation

\section{Hemodynamics}

For measurements of the regional CBF $(\mathrm{ml} / \mathrm{min} / 100 \mathrm{~g}$ tissue) a method with injection of gadolinium, dynamic susceptibility contrast MRI, or an ASL MRI approach as described above can be used [for reviews, see 58-60]. Dynamic susceptibility contrast MRI monitors the first passage of a bolus of intravenously injected contrast agent through the brain tissue. The presence of contrast agent results in a decay of the signal in a $\mathrm{T}_{2}{ }^{*}$-weighted image, which enables the monitoring of the time evolution of the contrast agent concentration by acquiring dynamic images of the brain. Quantification of the perfusion parameters requires measurements of the characteristics of the injected bolus [61-63]. This is called arterial input function (AIF) determination and is defined as the evolution in time of the contrast agent in the brain-feeding arteries. After correction of the passage through the brain tissue for the AIF, the response function is obtained. This response function reflects the hemodynamic properties of the microvasculature. From this response function both the $\mathrm{CBF}$ and several timing parameters for the contrast passage as well as blood volume can be calculated. Even with the acquisition of the AIF, further dispersion of the contrast bolus will occur from the arteries in the neck towards the microvasculature. This dispersion will result in uncertainties with respect to CBF quantification, especially in patients with steno-occlusive disease and delayed (collateral) flow [64, 65].

As described in detail in the previous anatomy section, with ASL the labeled protons pass through the arterial tree and exchange with the unlabeled brain tissue water. The change in tissue magnetization yields information on cerebral perfusion (fig. 5) [66, 67]. For CBF measurements a vast amount of ASL methods have been developed all using different labeling approaches for non-selec- 
Table 1. Most important magnetic resonance techniques for evaluation of the cerebral circulation in patients with steno-occlusive disease

\begin{tabular}{|c|c|c|c|}
\hline & $\begin{array}{l}\text { Level } 1 \\
\text { neck arteries }\end{array}$ & $\begin{array}{l}\text { Level } 2 \\
\text { circle of Willis }\end{array}$ & $\begin{array}{l}\text { Level } 3 \\
\text { brain perfusion }\end{array}$ \\
\hline \multicolumn{4}{|l|}{ Anatomy } \\
\hline Contrast & Contrast-enhanced & Contrast-enhanced & - \\
\hline Non-contrast & $\begin{array}{l}\text { 3D phase contrast } \\
\text { 3D time-of-flight }\end{array}$ & $\begin{array}{l}\text { 3D phase contrast } \\
\text { 3D time-of-flight }\end{array}$ & $\begin{array}{l}\text { Arterial spin labeling } \\
\text { (territory) }\end{array}$ \\
\hline \multicolumn{4}{|l|}{ Hemodynamics } \\
\hline Contrast & - & - & $\begin{array}{l}\text { Dynamic susceptibility } \\
\text { contrast }\end{array}$ \\
\hline Non-contrast & $\begin{array}{l}\text { 2D phase contrast } \\
\text { (volume flow) }\end{array}$ & $\begin{array}{l}\text { 2D phase contrast } \\
\text { (flow direction) } \\
\text { Dynamic angiography }\end{array}$ & Arterial spin labeling \\
\hline
\end{tabular}

A potential 20-min protocol to investigate the anatomy and hemodynamics at the three levels of the cerebral circulation consists of: contrast-enhanced and 2D phase contrast (volume flow) MRA of the neck arteries (level 1); 3D time-of-flight and 2D phase contrast (flow direction) MRA of the circle of Willis (level 2), and arterial spin labeling MRI at the brain tissue (level 3). 2D = Two-dimensional; 3D = three-dimensional. tive labeling of the vasculature proximal to the imaging region. Two major entities of ASL can be distinguished, pulsed ASL and continuous ASL [58, 59]. Pulsed ASL is obtained with a large proximal labeling volume (saturation or inversion pulse) at a single time point before imaging. With continuous ASL, a thin proximal labeling slice is applied over several seconds before imaging. The thin labeling slice is planned perpendicular to the ICAs and VBAs in the neck and blood passing through this labeling slice is magnetically labeled before imaging is performed. In patients with severe steno-occlusive disease the quantification of CBF with ASL is complicated due to the relatively large contribution of collateral flow to the cerebral perfusion. Labeled blood flowing via these collateral pathways will have a delayed arrival at the brain tissue, which results in an underestimation of the CBF. Several methods have been proposed to either correct for these differences in arterial transit time or measure the arterial transit time [48, 67-69].

\section{Conclusion}

In this overview we focused on the main MRA and MR perfusion techniques available to investigate the anatomy and function of the cerebral circulation in patients with steno-occlusive disease (table 1). We follow the journey of the blood from the aortic arch upwards with distribution of blood flow from the vessels in the neck (1st level), via the circle of Willis (2nd level) and its major branches towards the microvasculature and finally the brain tissue perfusion (3rd level). The combined use of MRA and MR perfusion techniques demonstrates that these three levels of the cerebral vasculature are closely related. For example, volume flow in the ICAs and BAs changes with differences in the morphology of the circle of Willis, and volume flow also correlates with the extension of the perfusion territories of individual arteries. To evaluate the cerebral hemodynamics in patients with obstructive arterial disease it is not sufficient to study one level of the cerebral circulation. It is important to investigate all three levels simultaneously in order to fully appreciate the role of collateral flow in the prognosis of these patients.

In addition to the close relation between these three levels of the cerebral circulation, there is significant interindividual variability within these levels in the general population. We believe that the combined use of the described MR methods will further enhance the understanding of the cerebral circulation both in health and disease and clarify pathophysiological relations between the vasculature, perfusion and brain function. 


\section{References}

$\checkmark 1$ Powers WJ: Cerebral hemodynamics in ischemic cerebrovascular disease. Ann Neurol 1991;29:231-240.

2 Caplan LR, Hennerici M: Impaired clearance of emboli (washout) is an important link between hypoperfusion, embolism, and ischemic stroke. Arch Neurol 1998;55:1475-1482.

$\checkmark 3$ Derdeyn CP, Grubb RLJ, Powers WJ: Cerebral hemodynamic impairment: methods of measurement and association with stroke risk. Neurology 1999;53:251-259.

-4 Klijn CJM, Kappelle LJ, Tulleken CAF, van Gijn J: Symptomatic carotid artery occlusion. A reappraisal of hemodynamic factors. Stroke 1997;28:2084-2093.

5 Osborne A: Diagnostic Cerebral Angiography. Philadelphia, Lippincott William \& Wilkins, 1999.

-6 Barnett HJM, Taylor DW, Eliasziw M, Fox AJ, Ferguson GG, Haynes RB, Rankin RN, Clagett GP, Hachinski VC, Sackett DL, Thorpe KE, Meldrum HE: Benefit of carotid endarterectomy in patients with symptomatic moderate or severe stenosis. N Engl J Med 1998;339: 1415-1425.

7 Randomised trial of endarterectomy for recently symptomatic carotid stenosis: final results of the MRC European Carotid Surgery Trial (ECST). Lancet 1998;351:1379-1387.

$\checkmark 8$ Henderson RD, Eliasziw M, Fox AJ, Rothwell PM, Barnett HJM: Angiographically defined collateral circulation and risk of stroke in patients with severe carotid artery stenosis. Stroke 2000;31:128-132.

$\checkmark 9$ Vernieri F, Pasqualetti P, Matteis M, Passarelli F, Troisi E, Rossini PM, Caltagirone C, Silvestrini M: Effect of collateral blood flow and cerebral vasomotor reactivity on the outcome of carotid artery occlusion. Stroke 2001;32: 1552-1558

10 Brozici M, van der ZA, Hillen B: Anatomy and functionality of leptomeningeal anastomoses: a review. Stroke 2003;34:2750-2762.

$>11$ Momjian-Mayor I, Baron JC: The pathophysiology of watershed infarction in internal carotid artery disease: review of cerebral perfusion studies. Stroke 2005;36:567-577.

12 Liebeskind DS: Collateral circulation. Stroke 2003;34:2279-2284.

- 13 Parker DL, Parker DJ, Blatter DD, Du YP, Goodrich KC: The effect of image resolution on vessel signal in high-resolution magnetic resonance angiography. J Magn Reson Imaging 1996;6:632-641.

-14 Hoogeveen RM, Bakker CJ, Viergever MA: Phase-derivative analysis in MR angiography: reduced Venc dependency and improved vessel wall detection in laminar and disturbed flow. J Magn Reson Imaging 1997; 7:321330 .

15 Mustert BR, Williams DM, Prince MR: In vitro model of arterial stenosis: correlation of MR signal dephasing and trans-stenotic pressure gradients. Magn Reson Imaging 1998;16: 301-310.
16 Kent KC, Kuntz KM, Patel MR, Kim D, Klufas RA, Whittemore AD, Polak JF, Skillman JJ, Edelman RR: Perioperative imaging strategies for carotid endarterectomy. An analysis of morbidity and cost-effectiveness in symptomatic patients. JAMA 1995;274:888-893.

17 Nederkoorn PJ, van der Graaf Y, Hunink MG: Duplex ultrasound and magnetic resonance angiography compared with digital subtraction angiography in carotid artery stenosis: a systematic review. Stroke 2003;34:1324-1332.

18 Willinek WA, Gieseke J, Conrad R, Strunk H, Hoogeveen R, von Falkenhausen M, Keller E, Urbach H, Kuhl CK, Schild HH: Randomly segmented central k-space ordering in highspatial-resolution contrast-enhanced MR angiography of the supraaortic arteries: initial experience. Radiology 2002;225:583-588.

19 Buskens E, Nederkoorn PJ, Buijs-Van Der Woude T, Mali WP, Kappelle LJ, Eikelboom BC, van der Graaf Y, Hunink MG: Imaging of carotid arteries in symptomatic patients: costeffectiveness of diagnostic strategies. Radiology 2004;233:101-112.

$\checkmark 20$ Nederkoorn PJ, Elgersma OE, van der Graaf Y, Eikelboom BC, Kappelle LJ, Mali WP: Carotid artery stenosis: accuracy of contrast-enhanced MR angiography for diagnosis. Radiology 2003;228:677-682.

21 Willinek WA, von Falkenhausen M, Born M, Gieseke J, Holler T, Klockgether T, Textor HJ, Schild HH, Urbach H: Noninvasive detection of steno-occlusive disease of the supra-aortic arteries with three-dimensional contrast-enhanced magnetic resonance angiography: a prospective, intra-individual comparative analysis with digital subtraction angiography. Stroke 2005;36:38-43.

22 Saito K, Kimura K, Nagatsuka K, Nagano K, Minematsu K, Ueno S, Naritomi H: Vertebral artery occlusion in duplex color-coded ultrasonography. Stroke 2004;35:1068-1072.

23 Amin-Hanjani S, Du X, Zhao M, Walsh K, Malisch TW, Charbel FT: Use of quantitative magnetic resonance angiography to stratify stroke risk in symptomatic vertebrobasilar disease. Stroke 2005;36:1140-1145.

24 Firmin DN, Nayler GL, Klipstein RH, Underwood SR, Rees RSO, Longmore DB: In vivo validation of MR velocity imaging. J Comput Assist Tomogr 1987;11:751-756.

25 Bendel P, Buonocore E, Bockisch A, Besozzi $\mathrm{MC}$ : Blood flow in the carotid arteries: quantification by using phase-sensitive MR imaging. AJR Am J Roentgenol 1989;152:1307-1310.

26 Enzmann DR, Marks MP, Pelc NJ: Comparison of cerebral artery blood flow measurements with gated cine and ungated phase-contrast techniques. J Magn Reson Imaging 1993;3: 705-712.
27 Bakker CJG, Kouwenhoven M, Hartkamp MJ, Hoogeveen RM, Mali WPTM: Accuracy and precision of time-averaged flow as measured by non-triggered 2D phase-contrast MR angiography: a phantom evaluation. Magn Reson Imaging 1995; 13:959-965.

28 Bakker CJG, Hartkamp MJ, Mali WPTM: Measuring blood flow by nontriggered 2D phase contrast MR angiography. Magn Reson Imaging 1996; 14:609-614.

29 Spilt A, Box FM, van der Geest RJ, Reiber JH, Kunz P, Kamper AM, Blauw GJ, van Buchem MA: Reproducibility of total cerebral blood flow measurements using phase contrast magnetic resonance imaging. J Magn Reson Imaging 2002;16:1-5.

30 van Everdingen KJ, Klijn CJM, Kappelle LJ, Mali WPTM, Van der Grond J: MRA flow quantification in patients with a symptomatic internal carotid artery occlusion. Stroke 1997; 28:1595-1600.

-31 Hendrikse J, van Raamt AF, van der Graaf Y, Mali WP, van der Grond J: Distribution of cerebral blood flow in the circle of Willis. Radiology 2005;235:184-189.

32 Krabbe Hartkamp MJ, Van der Grond J, de Leeuw FE, de Groot JC, Algra A, Hillen B, Breteler MM, Mali WPTM: Circle of Willis: morphologic variation on three-dimensional timeof-flight MR angiograms. Radiology 1998;207: 103-111.

33 Hoksbergen AW, Majoie CB, Hulsmans FJ, Legemate DA: Assessment of the collateral function of the circle of Willis: three-dimensional time-of-flight MR angiography compared with transcranial color-coded duplex sonography. AJNR Am J Neuroradiol 2003;24: 456-462.

>34 Hendrikse J, Eikelboom BC, Van der Grond J: Magnetic resonance angiography of collateral compensation in asymptomatic and symptomatic internal carotid artery stenosis. J Vasc Surg 2002;36:799-805.

35 Schomer DF, Marks MP, Steinberg GK, Johnstone IM, Boothroyd DB, Ross MR, Pelc NJ, Enzmann DR: The anatomy of the posterior communicating artery as a risk factor for ischemic cerebral infarction. N Engl J Med 1994; 330:1565-1570.

-36 Hartkamp MJ, Van der Grond J, van Everdingen KJ, Hillen B, Mali WPTM: Circle of willis collateral flow investigated by magnetic resonance angiography. Stroke 1999;30:26712678.

37 Hoogeveen RM, Bakker CJ, Viergever MA: Limits to the accuracy of vessel diameter measurement in MR angiography. J Magn Reson Imaging 1998;8:1228-1235.

38 Pernicone JR, Siebert JE, Laird TA, Rosenbaum TL, Potchen EJ: Determination of blood flow direction using velocity-phase image display with 3-D phase-contrast MR angiography. AJNR Am J Neuroradiol 1992;13:14351438 . 
>39 Ross MR, Pelc NJ, Enzmann DR: Qualitative phase contrast MRA in the normal and abnormal circle of Willis. AJNR Am J Neuroradiol 1993;14:19-25.

-40 Miralles M, Dolz JL, Cotillas J, Aldoma J, Santiso MA, Gimenez A, Capdevila A, Cairols MA: The role of the circle of Willis in carotid occlusion: assessment with phase contrast MR angiography and transcranial duplex. Eur J Vasc Endovasc Surg 1995;10:424-430.

-41 Rutgers DR, Klijn CJM, Kappelle LJ, van Huffelen AC, Van der Grond J: A longitudinal study of collateral flow patterns in the circle of Willis and the ophthalmic artery in patients with a symptomatic internal carotid artery occlusion. Stroke 2000;31:1913-1920.

42 Hendrikse J, Rutgers DR, Klijn CJ, Eikelboom BC, Van der Grond J: Effect of carotid endarterectomy on primary collateral blood flow in patients with severe carotid artery lesions. Stroke 2003;34:1650-1654.

43 Enzmann DR, Ross MR, Marks MP, Pelc NJ: Bloodflow in major cerebral arteries measured by phase contrast cine MR. AJNR Am J Neuroradiol 1994;15:123-129.

44 van Osch MJ, Hendrikse J, Golay X, Bakker CJ, van der Grond J: Non-invasive visualization of collateral blood flow patterns of the circle of Willis by dynamic MR angiography. Med Image Anal 2006;10:59-70.

-45 Gauvrit JY, Leclerc X, Oppenheim C, Munier T, Trystram D, Rachdi H, Nataf F, Pruvo JP, Meder JF: Three-dimensional dynamic MR digital subtraction angiography using sensitivity encoding for the evaluation of intracranial arteriovenous malformations: a preliminary study. AJNR Am J Neuroradiol 2005;26: 1525-1531.

-46 Warren DJ, Hoggard N, Walton L, Radatz MW, Kemeny AA, Forster DM, Wilkinson ID, Griffiths PD: Cerebral arteriovenous malformations: comparison of novel magnetic resonance angiographic techniques and conventional catheter angiography. Neurosurgery 2001;48:973-982.

-47 Edelman RR, Mattle HP, O'Reilly GV, Wentz KU, Liu C, Zhao B: Magnetic Resonance Imaging of flow dynamics in the circle of Willis. Stroke 1990;21:56-65.
48 Warmuth C, Ruping M, Forschler A, Koennecke HC, Valdueza JM, Kauert A, Schreiber SJ, Siekmann R, Zimmer C: Dynamic spin labeling angiography in extracranial carotid artery stenosis. AJNR Am J Neuroradiol 2005; 26:1035-1043.

49 Hendrikse J, van der Grond J, Lu H, van Zijl PC, Golay X: Flow territory mapping of the cerebral arteries with regional perfusion MRI. Stroke 2004;35:882-887.

50 Davies NP, Jezzard P: Selective arterial spin labeling (SASL): perfusion territory mapping of selected feeding arteries tagged using twodimensional radiofrequency pulses. Magn Reson Med 2003;49:1133-1142.

-51 Taoka T, Iwasaki S, Nakagawa H, Fukusumi A, Hirohashi S, Sakamoto M, Kichikawa K, Murata K: Distinguishing between anterior cerebral artery and middle cerebral artery perfusion by color-coded perfusion direction mapping with arterial spin labeling. AJNR Am J Neuroradiol 2004;25:248-251.

52 Werner R, Norris DG, Alfke K, Mehdorn HM, Jansen O: Continuous artery-selective spin labeling (CASSL). Magn Reson Med 2005;53: 1006-1012.

53 Trampel R, Mildner T, Goerke U, Schaefer A, Driesel W, Norris DG: Continuous arterial spin labeling using a local magnetic field gradient coil. Magn Reson Med 2002;48:543-546.

54 Zaharchuk G, Ledden PJ, Kwong KK, Reese TG, Rosen BR, Wald LL: Multislice perfusion and perfusion territory imaging in humans with separate label and image coils. Magn Reson Med 1999;41:1093-1098.

55 Werner R, Alfke K, Schaeffter T, Nabavi A, Mehdorn HM, Jansen O: Brain perfusion territory imaging applying oblique-plane arterial spin labeling with a standard send/receive head coil. Magn Reson Med 2004;52:1443-1447.

56 van der Zwan A, Hillen B, Tulleken CAF, Dujovny M, Dragovic L: Variability of the territories of the major cerebral arteries. J Neurosurg 1992; 77:927-940.

>57 Van Laar PJ, Hendrikse J, Golay X, Lu H, van Osch MJP, Van der Grond J: In vivo flow territory mapping of major brain feeding arteries. Neuroimage 2006;1:136-144.

>58 Detre JA, Alsop DC: Perfusion magnetic resonance imaging with continuous arterial spin labeling: methods and clinical applications in the central nervous system. Eur J Radiol 1999; 30:115-124.
59 Calamante F, Thomas DL, Pell GS, Wiersma J, Turner R: Measuring cerebral blood flow using magnetic resonance imaging techniques. $\mathrm{J}$ Cereb Blood Flow Metab 1999; 19:701-735.

60 Barbier EL, Lamalle L, Decorps M: Methodology of brain perfusion imaging. J Magn Reson Imaging 2001;13:496-520.

61 Rempp KA, Brix G, Wenz F, Becker CR, Gückel F, Lorenz WJ: Quantification of regional cerebral bloodflow and volume with dynamic susceptibility contrast-enhanced MR Imaging. Radiology 1994;193:637-641.

62 Ostergaard L, Weisskoff RM, Chesler DA, Gyldensted C, Rosen BR: High resolution measurement of cerebral blood flow using intravascular tracer bolus passages. Part I: Mathematical approach and statistical analysis. Magn Reson Med 1996;36:715-725.

63 Vonken EJ, van Osch MJ, Bakker CJ, Viergever MA: Measurement of cerebral perfusion with dual-echo multi-slice quantitative dynamic susceptibility contrast MRI. J Magn Reson Imaging 1999;10:109-117.

64 Weisskoff RM, Chesler D, Boxerman JL, Rosen BR: Pitfalls in MR measurement of tissue blood flow with intravascular tracers: which mean transit time? Magn Reson Med 1993;29:553-558.

-65 Perthen JE, Calamante F, Gadian DG, Connelly A: Is quantification of bolus tracking MRI reliable without deconvolution? Magn Reson Med 2002;47:61-67.

66 Calamante F, Williams SR, van Bruggen N, Kwong KK, Turner R: A model for quantification of perfusion in pulsed labelling techniques. NMR Biomed 1996;9:79-83.

67 Buxton RB, Frank LR, Wong EC, Siewert B, Warach S, Edelman RR: A general kinetic model for quantitative perfusion imaging with arterial spin labeling. Magn Reson Med 1998; 40:383-396.

68 Gonzalez-At JB, Alsop DC, Detre JA: Cerebral perfusion and arterial transit time changes during task activation determined with continuous arterial spin labeling. Magn Reson Med 2000;43:739-746.

69 Hendrikse J, van Osch MJ, Rutgers DR, Bakker CJ, Kappelle LJ, Golay X, van der Grond $\mathrm{J}$ : Internal carotid artery occlusion assessed at pulsed arterial spin-labeling perfusion MR imaging at multiple delay times. Radiology 2004; 233:899-904. 